dementia with Mini-Mental scores between 0 and 14/30 without amyloid deposits and with neuritic Braak stages I or II. These were found among 150 consecutive cases of the Vienna Longitudinal Study on Dementia, ${ }^{15}$ in which elderly patients underwent prospective clinical and psychometric examination at least every six months. The six patients, only three of whom had a history of previous stroke, are summarized in the Table. There were four males and two females aged at death between 67 and 93 years with duration of dementia between 3 and 7 years. Clinical diagnosis was probable $\mathrm{AD}$ in four, VD and Parkinson's disease in one, and VD in one. At autopsy, all brains except one showed severe atherosclerosis of the cerebral arteries, with hypertensive microangiopathy in four. All brains except one showed rather small left or bilateral infarcts in the medial thalamus. Severe lacunar state in basal ganglia or brainstem were seen in two. Additional old putaminal hemorrhage and left PCA infarction were seen in one each. None of these brains showed amyloid deposits/angiopathy or neuritic plaques; hence, all current neuropathologic AD criteria were negative. These data confirm the notion that VD unaccompanied by neuropathologic evidence of $\mathrm{AD}$ is rare. $\mathrm{As}$ demonstrated by our cohort, VD may often be related to small or medium-sized strategic infarcts mainly involving the thalamus without gross infarctions in cerebral hemispheres. ${ }^{16}$

\section{K.A. Jellinger}

Vienna, Austria

Reply from the Authors: We agree with Drs. Moroney and Desmond that our study was not carried out using a population-based sample. It was not, however, a referral sample focused on $\mathrm{AD}$ as they suggest. The neuropathologists at 10 medical centers were asked to submit "any" cases with progressive dementia clinically diagnosed as $\mathrm{AD}$ or multi-infarct dementia in which the autopsy revealed only cerebral infarction. CERAD criteria were not requisite for our study. Only one of our six cases, in fact, met CERAD criteria for the clinical diagnosis of probable $\mathrm{AD}$.

As pointed out, the definition of progressive dementia may be subjective, but cases included had cognitive impairment sufficient to interfere with social and occupational function. Drs. Moroney and Desmond appropriately note that the neuropathology assessment was limited in several cases to one hemisphere. Although this approach may underestimate the extent and nature of vascular pathology, unilateral examination is adequate to assess $\mathrm{AD}$ changes. We agree that prospective clinicopathologic studies of patients with dementia and evidence of cerebrovascular disease are needed. Nonetheless, we believe that our study, despite inherent methodologic limitations acknowledged in our report, highlights the relative infrequency with which vascular dementia presents to neuropathologists at major medical centers. We were pleased to learn that Dr. Jellinger's extensive experience validates our findings.

\section{Christine $M$. Hulette, $M D$}

Albert Heyman, $M D$

\section{Durham, NC}

David Nochlin, $M D$

S. Mark Sumi, $M D$

Seattle, WA
Dan McKeel, $M D$

John C. Morris, MD

\section{St. Louis, MO}

Suzanne S. Mirra, MD

Atlanta, GA

Copyright $(\mathcal{O} 1997$ by the American Academy of Neurology

\section{References}

1. Hulette C, Nochlin D, McKeel D, et al. Clinical-neuropathologie find ings in multi-infarct dementia: a report of six autopsied cases. Neurology 1997;48:668-672.

2. Desmond DW. Vascular dementia: a construct in evolution. Cerobral Brain Met Rev 1996;8:296-325.

3. Morris JC, Heyman A, Mohs RC, et al. The Consortium to Establish a Registry for Alzheimer's Disease (CERAD). Part 1. Clinical and neuro. logical assessment of Alzheimer's disease. Neurology 1989;39:11591165 .

4. Desmond DW, Moroney JT, Sano M, Stern Y. Recovery of cognitive function after stroke. Stroke 1996;27:1798-1803.

5. Tatemichi TK, Paik M, Bagiella E, et al. Risk of dementia after stroke in a hospitalized cohort: results of a longitudinal study. Neurology 1994; 44:1885-1891.

6. Moroney JT, Bagiella E, Desmond DW, Paik MC, Stern Y, Tatemichi TK. Risk factors for incident dementia after stroke: role of hypoxic and ischemic disorders. Stroke 1996;27:1283-1289.

7. Tatemichi TK, Desmond DW, Prohovnik I. Strategic infarcts in vascular' dementia: a clinical and brain imaging experience. Arzneimittel. Forschung 1995;45:371-385.

8. Brun A, Englund E. A white matter disorder in dementia of Alzheimer type: a pathoanatomical study. Ann Neurol 1986;19:253-262.

9. Gearing M, Mirra SS, Hedreen JC, Sumi SM, Hansen I.A, Hyman A The Consortium to Establish a Registry for Alzheimer's Disease (CERAD). Part X. Neuropathology confirmation of the clinical diagnowis of Alzheimer's disease. Neurology 1995;45:461-566.

10. Olichney JM, Hansen LA, Hofsetta CR, Grundman M, Katzman R, Thal Lu. Cerebral infarction in Alzheimer's disease is associated with severe amyloid angiopathy and hypertension. Arch Neurol 1995;52:702-708.

11. Snowdon DA, Greiner LH, Mortimer JA, Riley KP, Greiner PA, Markesbery WR. Brain infaretion and the clinical expression of Alzhoimer's disease. The Nun Study. JAMA 1997;277:813-817.

12. Moroney JT, Bagiella E, Desmond DW, et al. Meta-analysis of the Hachinski ischemic score in pathologically verified dementias. Neurology (in press).

13. Kokmen E, Whisnant JP, O'Fallon WM, Chu CP, Beard CM. Dementiat after ischemic stroke: a population-based study in Rochester, Minnesota (1960-1984). Neurology 1996;19:154-159.

14. Jellinger KA. Structural basis of dementia in neurodegenerative disorders. J Neural Transm 1996;suppl. 47:1-29.

15. Bancher C, Jellinger K, Lassmann H, Fischer P, Leblhuber F. Correlations between mental state and quantitative neuropathology in the Vienna Longitudinal Study on Dementia. Eur Arch Psychiatry Clin Neurasci 1996;246:137-146.

16. Jellinger KA, Bancher C. Classification of dementias based on functional morphology. In: Jellinger KA, Ladurner G, Windisch M, eds. New Trends in the Diagnosis and Therapy of Alzheimer's Disease. WienNew York: Springer-Verlag; 1994:9-39.

\title{
Correction
}

In the article "What are the obstacles for an accurate clinical diagnosis of Pick's disease? A clinicopathologic study" by Litvan et al. (Neurology 1997;49:62-69), N. Sastry's name was misspelled. We apologize for any inconvenience or confusion this may have caused. 


\title{
Neurology
}

\author{
Correction \\ Neurology 1997;49;1755-1755-a \\ DOI 10.1212/WNL.49.6.1755-a
}

This information is current as of December 1, 1997

\section{Updated Information \& \\ Services}

Permissions \& Licensing

Reprints including high resolution figures, can be found at:

http://n.neurology.org/content/49/6/1755.2.full

Information about reproducing this article in parts (figures,tables) or in its entirety can be found online at:

http://www.neurology.org/about/about_the_journal\#permissions

Information about ordering reprints can be found online:

http://n.neurology.org/subscribers/advertise

Neurology $®$ is the official journal of the American Academy of Neurology. Published continuously since 1951, it is now a weekly with 48 issues per year. Copyright. All rights reserved. Print ISSN: 0028-3878. Online ISSN: 1526-632X.

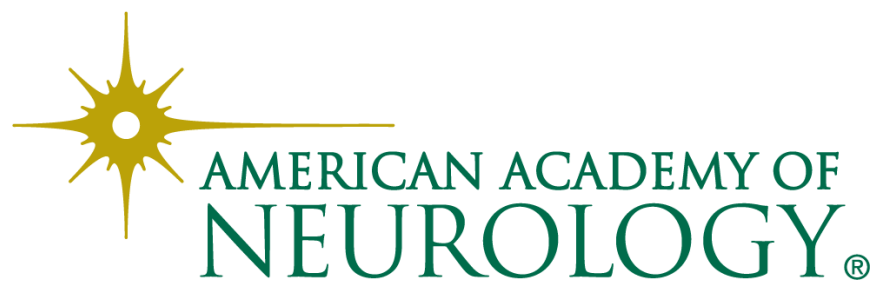

